\title{
НОВОЕ ОБОРУДОВАНИЕ ДЛЯ ТРАВЛЕНИЯ КРЕМНИЕВЫХ СТРУКТУР НА ПЛАСТИНАХ ДИАМЕТРОМ ДО 200 ММ
}

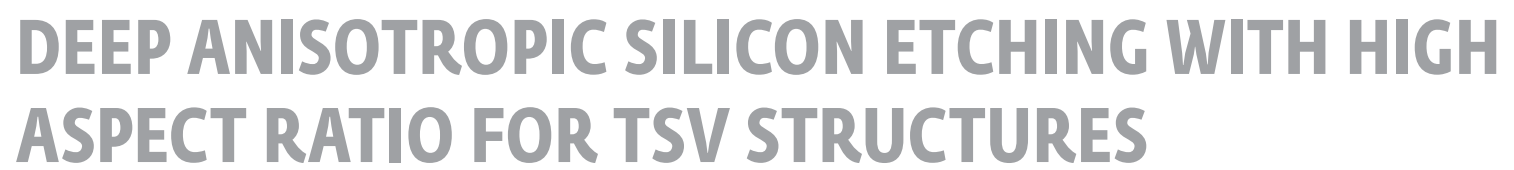

В.М.Долгополов', к.т.н., (ORCID ID: 0000-0002-9678-9178), В.В.Одиноков', д.т.н, проф., (ORCID ID: 0000-00031652-8013), П.А.Иракин' (ORCID ID: 0000-0002-1513-1105), В.М.Варакин', (ORCID ID: 0000-0002-5952-0911) / marketing@niitm.ru

V.M.Dolgopolov', Cand. of Sc. (Technical), (ORCID ID: 0000-0002-9678-9178), V.V.Odinokov', Doct. of Sc. (Technical), Prof., (ORCID ID: 0000-0003-1652-8013), P.A.Irakin', (ORCID ID: 0000-0002-1513-1705), V.M.Varakin (ORCID ID: 0000-0002-5952-0911)

DOI: 10.22184/1993-8578.2019.12.5.268.274, УДК: 621.315.592:546.28

Получено: 19.08.2019 г.

При изготовлении трехмерных структур с применением технологии формирования глубоких отверстий в кремнии, а также при изготовлении микроэлектромеханических систем широкое распространение получил процесс глубокого анизотропного травления кремния с применением попеременных процессов травления и пассивации. Суть процесса заключается в чередовании стадий реактивно-ионного травления поверхности кремния (как правило, в $\mathrm{SF}_{6}$ ) и пассивации поверхности (как правило, с применением $\mathrm{C}_{4} \mathrm{~F}_{8}$ ) [1, 2]. При этом на стадии травления пассивирующий слой удаляется со дна канавок быстрее, чем со стенок, что в итоге позволяет получить анизотропность процесса травления. К преимуществам процесса можно отнести: проведение процесса при комнатных температурах, высокую селективность к фоторезисту (около 80:1 и более), получение структур с аспектным отношением до 30: 1 [3], скорость травления до 20 мкм/мин, а также контролируемый профиль травления [4]. Основным недостатком процесса является шероховатость стенок в связи с цикличностью процесса. Цель данной работы - создание реактора для глубокого плазмохимического травления кремния на пластинах диаметром до 200 мм, аналогичного по своим характеристикам импортному, и разработка технологии глубокого травления кремния для ее применения в изготовлении трехмерных TSV-структур.

Process of deep anisotropic silicon etching with alternating steps of etching and passivation process) is widely used for forming three-dimensional structures with through-silicon-vias, as well as in the manufacturing of micro electromechanical systems. The essence of the process lies in alternating steps of reactive-ion etching of silicon (usually $\mathrm{SF}_{6}$ ) and passivation of the surface (typically by using $\mathrm{C}_{4} \mathrm{~F}_{8}$ ) [1, 2]. Herewith the step of etching the passivation layer removing from the bottom of the grooves are faster than from the walls, with the result that allows to obtain anisotropic etching process. Advantages of the process include: carrying out the process at room temperatures, high photoresist selectivity (about 80:1 and more), the preparation of structures with an aspect ratio of $30: 1$ [3], the etch rate up to $20 \mu \mathrm{m} / \mathrm{min}$ and controlled etching profile [4]. The main drawback of the process is the roughness of the walls (scallops) in connection with the cyclical process. The aim of this work was to develop a reactor for deep silicon etching on wafers diameter of up to $200 \mathrm{~mm}$, similar in their characteristics with import and development of technology deep silicon etching for its use in the manufacture of three-dimensional TSV assembly.

Открытое акционерное общество Научно-исследовательский институт точного машиностроения (OAO HИИтM) / Research institute of precision machine manufacturing (NIITM) 


\section{EQUIPMENT FOR NANOINDUSTRY}

B настоящее время технология формирования глубоких отверстий в кремнии (throughsilicon vias, TSV) представляет большой интерес для отечественной микроэлектроники. Кроме того, важным этапом формирования ИС является изготовление изоляции элементов в кремниевой подложке. С момента, как полупроводниковая промышленность достигла критического размера 0,25 мкм, для изоляции элементов применяется технология мелкощелевой изоляции (shallow trench isolation (STI)).

Основным преимуществом технологии TSV является улучшение характеристик изделий при уменьшении занимаемой площади. Так, фирмы Samsung Electronics [5] (Южная Корея) и Micron Technology [6] (США) разработали чипы памяти с применением технологии TSV, пропускная способность которых была увеличена вплоть до 320 Гб/с. При этом данные чипы требуют примерно на 70\% меньше энергии чем существующие на дан ${ }^{-}$ ный момент чипы DDR3 [7]. Однако, необходимое промышленное оборудование может быть представлено только импортными образцами ведущих разработчиков (LAM, SPTS) и имеет большую стоимость.

При формировании TSV-структур на боковых стенках отверстий остается трудноудаляемый полимерный слой. Для решения этой проблемы требуется разработка реакторов с высокой плотностью плазмы.

Отработка реакторов и технологии для глубокого травления кремния, поликремния, мелкощелевой изоляции и удаления полимерных слоев проводились на базе установок "Плазма Тм 200-01", "Плазма ТМ 200-02", "Плазма ТМ 200-03", разработанных в ОАО "НИИ точного машиностроения".

Цель данной работы - создание реактора для глубокого плазмохимического травления (ПХТ) кремния на пластинах диаметром до 200 мм, аналогичного по своим характеристикам импортному, и разработка технологии глубокого травления кремния для ее применения в изготовлении трехмерных TSV-структур. Кроме того, были разработаны реакторы для ПХТ мелкощелевой изоляции, поликремниевых затворов и СВЧ-очистки поверхности пластин от органических загрязнений и остатков фоторезиста.

Экспериментальные образцы были исследованы на сколах при помощи растрового электронного микроскопа.

Получены значения неоднородности процесса травления в пределах 2-3\%, глубокие отверстия и

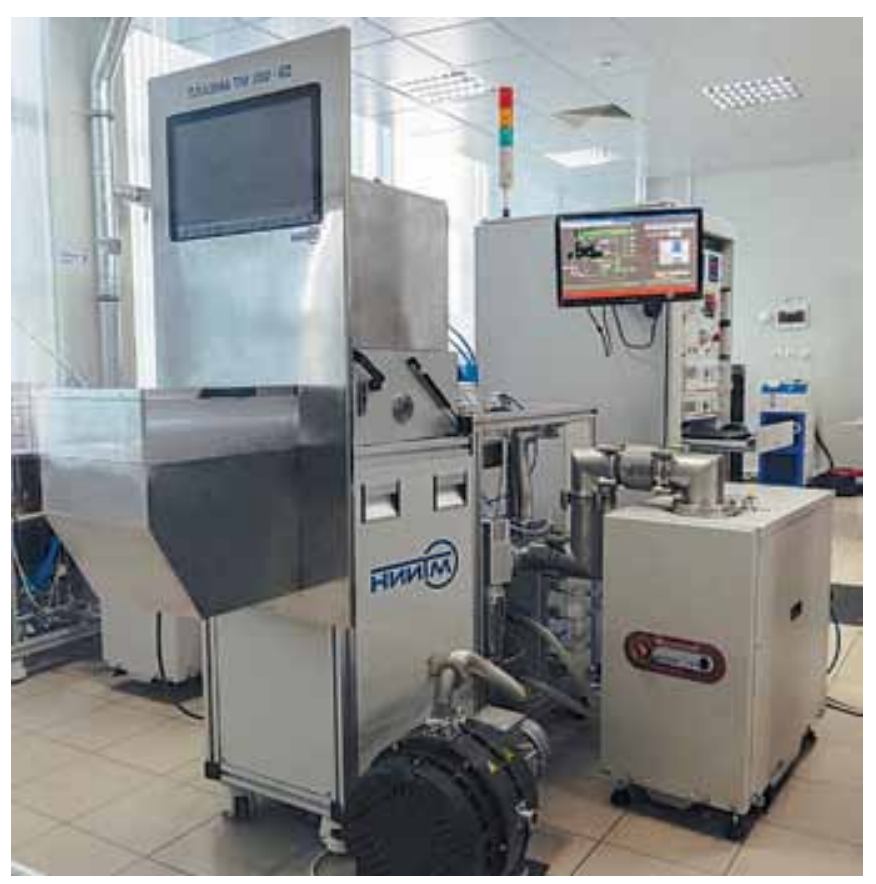

Pис.1. Установка глубокого анизотропного травления "Плазма ТМ 200-02K"

Fig.1. Installation for deep anisotropic etching Plazma TM 200-02K

щели с большим аспектным соотношением (более 15) и низкой шероховатостью стенок (75-100 нм) при скорости травления кремния до 5 мкм/мин, что позволяет применять установку в промышленном производстве.

\section{ЭКСПЕРИМЕНТ}

Отработка реактора и технологии для глубокого травления кремния проводились на базе конструктива установки "Плазма ТМ 200-02", разработанной в ОАО "НИИ точного машиностроения". Внешний вид установки представлен на рис.1. Схема реактора представлена на рис.2. Разряд зажигается в реакционной камере диаметром 400 мм ICР-источником с помощью ВЧ-генератора (частота 13,56 МГц, мощность до 3 кВт) через согласующее устройство. Для задания необходимого отрицательного смещения на охлаждаемый электрод-подложкодержатель от отдельного ВЧ-генератора (частота 13,56 МГц, мощность до 300 Вт) через согласующее устройство подавалось смещение. Высоковакуумная система откачки на базе турбомолекулярного и форвакуумного насосов обеспечивала предельный остаточный вакуум $1 \cdot 10^{-3}$ Па.

Отработка реактора и технологии для травления поликристаллического кремния и 


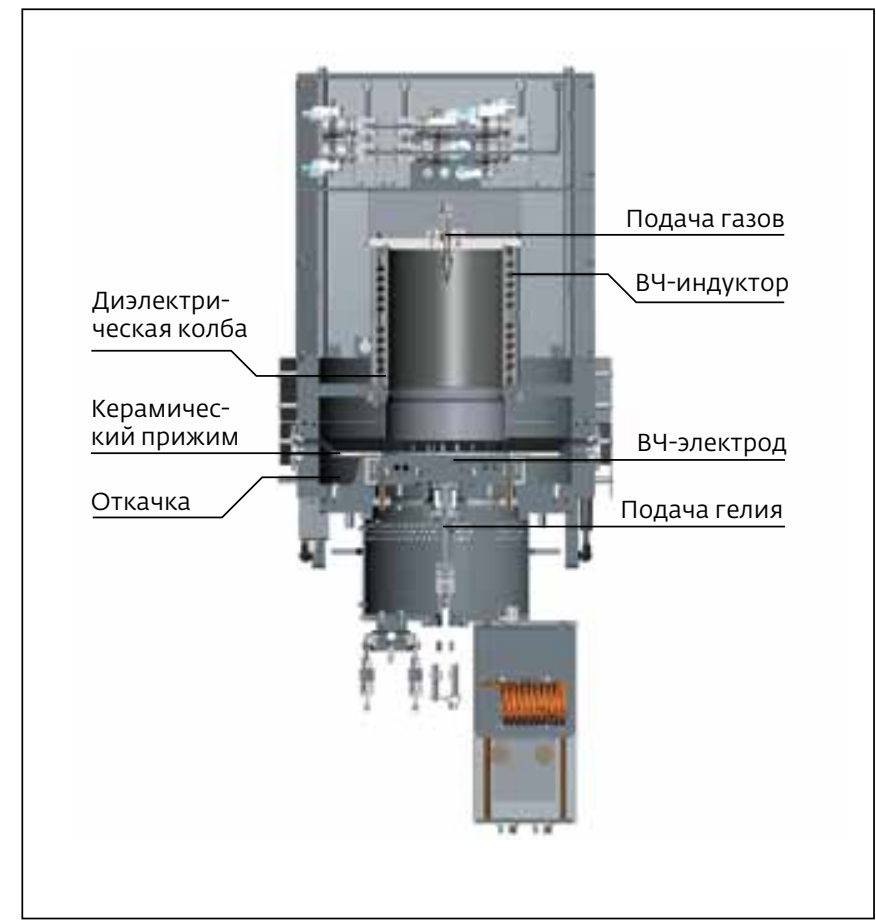

Pис.2. Схема реактора установки "Пиазма ТМ 200-02" Fig.2. Reactor diagram of Plazma TM 200-02 installation

Таблица 1. Параметры технологического режима для глубокого анизотропного травления кремния

Table 7. Parameters of technological mode for deep anisotropic etching of silicon

\begin{tabular}{|c|c|c|c|}
\hline Стадия & Травление 1 & Травление 2 & Пассивация \\
\hline Расход Ar, л/ч & 2 & 2 & 2 \\
\hline Расход $\mathrm{SF}_{6}, л / ч$ & 120 & 120 & 0 \\
\hline Расход $\mathrm{C}_{4} \mathrm{~F}_{8}, \pi / 4$ & 0 & 0 & 80 \\
\hline Давление, Па & 4 & 4 & 3 \\
\hline $\begin{array}{l}\text { Мощность } \\
\text { источника } \\
\text { плазмы, Вт }\end{array}$ & $1000 / 36$ & $1000 / 44$ & $1200 / 29$ \\
\hline $\begin{array}{l}\text { Мощность под- } \\
\text { ложкодержа- } \\
\text { теля, Вт }\end{array}$ & $90 / 51$ & $40 / 33$ & $8 / 8$ \\
\hline Смещение, В & 147 & 70 & 14 \\
\hline Время, с & 1,5 & 1,5 & $2-6$ \\
\hline $\begin{array}{l}\text { Количество } \\
\text { циклов }\end{array}$ & $100-250$ & $100-250$ & $100-250$ \\
\hline $\begin{array}{l}\text { Расход гелия под } \\
\text { пластиной, л/ч }\end{array}$ & 0,36 & 0,36 & 0,36 \\
\hline
\end{tabular}

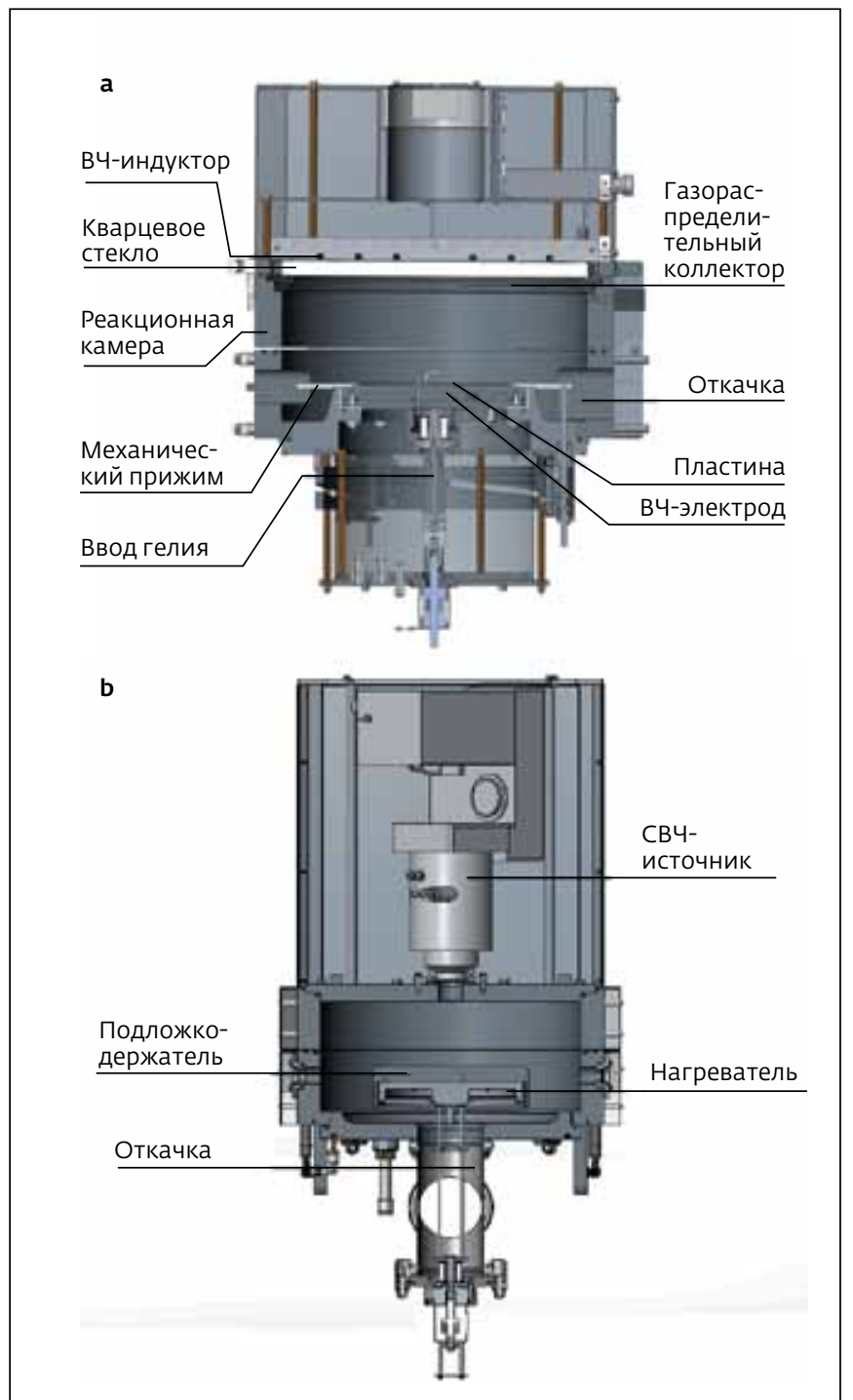

Puc.3. Схема реакторов установки "Плазма ТМ 200-01" (a) и "Плазма ТМ 200-03" (b)

Fig.3. Diagrams of Plazma TM 200-01 (a) and Plazma TM 200-03 (b) reactors

мелкощелевой изоляции в кремнии проводилась на базе конструктива установки "Плазма ТМ 200-01", аналогично установке "Плазма ТМ 200-02". Схема реактора представлена на рис.3а.

Отработка реактора и технологии для очистки от остатков фоторезиста и боковых стенок отверстий от трудноудаляемого полимерного слоя проводилась на базе конструктива установки "Плазма ТМ 200-03", аналогично установке "Плазма Тм 200-01". Схема реактора представлена на рис.3b.

\section{РЕЗУЛЬТАТЫ ЭКСПЕРИМЕНТОВ}

Эксперименты по глубокому анизотропному травлению кремния проводились на пластинах 

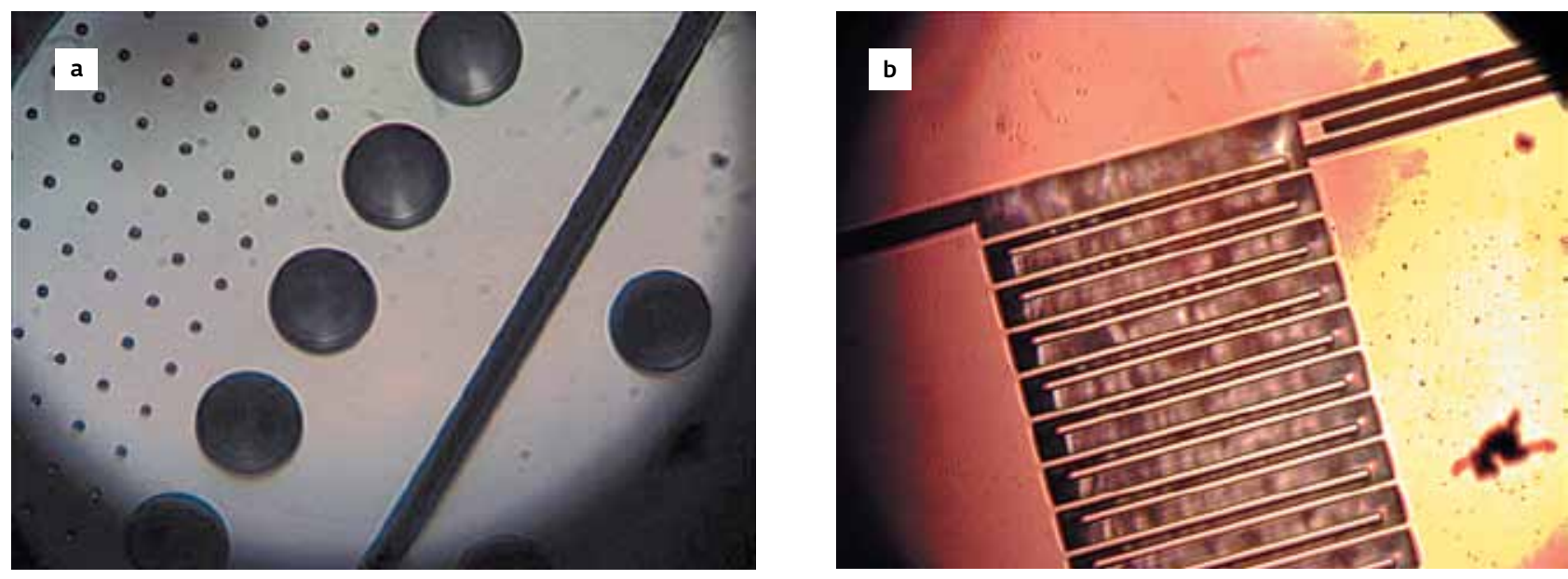

Puc.4. Снимки на микроскопе МИИ-4 пластин 200 мм (a) и 100 мм (b)

Fig.4. Images obtained by MII-4 microscope of $200 \mathrm{~mm}$ (a) and $100 \mathrm{~mm}$ (b) wafers

диаметром 200 мм. На них предварительно были сформированы маски из оксида кремния толщиной 0,6 мкм и фоторезиста толщиной 2,2 мкм. Топология маски включала отверстия диаметрами 2, 3, 5 и 10 мкм. При получении приемлемого показателя неоднородности травления по пластине, наряду с пластинами диаметром 200 мм, были проведены эксперименты на пластинах диаметром 100 мм. Фотографии поверхностей пластин 200 и 100 мм под микроскопом приведены на рис.4, а режимы травления представлены в табл. 1.

Наряду с отработкой процесса глубокого анизотропного травления кремния на установке "Плазма ТМ 200-02" отрабатывались процессы травления мелкощелевой изоляции в кремнии и поликремниевых затворов. В качестве маски мелкощелевой изоляции использовался фоторезист толщиной 2,2 мкм с подслоем $\mathrm{SiO}_{2}$ толщиной 12 нм и $\mathrm{Si}_{3} \mathrm{~N}_{4}$ толщиной 160 нм. Режимы травления представлены в табл. 2.

Результаты процесса травления на пластинах диаметром 200 мм в установке "Плазма Тм 200-02" приведены на рис.5.

Основные характеристики процесса травления:

- средняя скорость травления кремния : $\approx 2,36 \mathrm{M} \mathrm{км} / \mathrm{мин;}$

- равномерность травления, измеренная в стандартных пяти точках: $\approx 1,77 \%$;

- средняя селективность к маске: $\approx 25: 1$;

- подтрав под маску: ₹286-556 нм;

- угол наклона профиля: $\approx 90 \pm 0,5^{\circ}$;

- величина scallop менее 100 нм.
Результаты процесса травления на пластинах диаметром 100 мм в установке "Плазма ТМ 200-01" приведены на рис.6.

Основные характеристики процесса травления:

- средняя скорость травления кремния: $\approx 5 \mathrm{MKм} / \mathrm{Mин;}$

- равномерность травления, измеренная в стандартных пяти точках: $\approx 1,5 \%$;

- средняя селективность к маске: $\approx 25: 1$;

- подтрав под маску: ₹529 нм;

Таблица 2. Параметры технологического режима для мелкощелевой изоляции и поликремниевых затворов

Table 2. Parameters of technological mode for shallow trench isolation and polycrystalline silicon gate

\begin{tabular}{|l|c|}
\hline Расход $\mathrm{SF}_{6}$, л/ч & 12 \\
\hline Расход $\mathrm{C}_{4} \mathrm{~F}_{8}$, л/ч & 16 \\
\hline Давление, Па & 9 \\
\hline Мощность источника плазмы, Вт & 1000 \\
\hline Мощность подложкодержателя, Вт & 40 \\
\hline Смещение, В & 100 \\
\hline Время, с & 150 \\
\hline
\end{tabular}



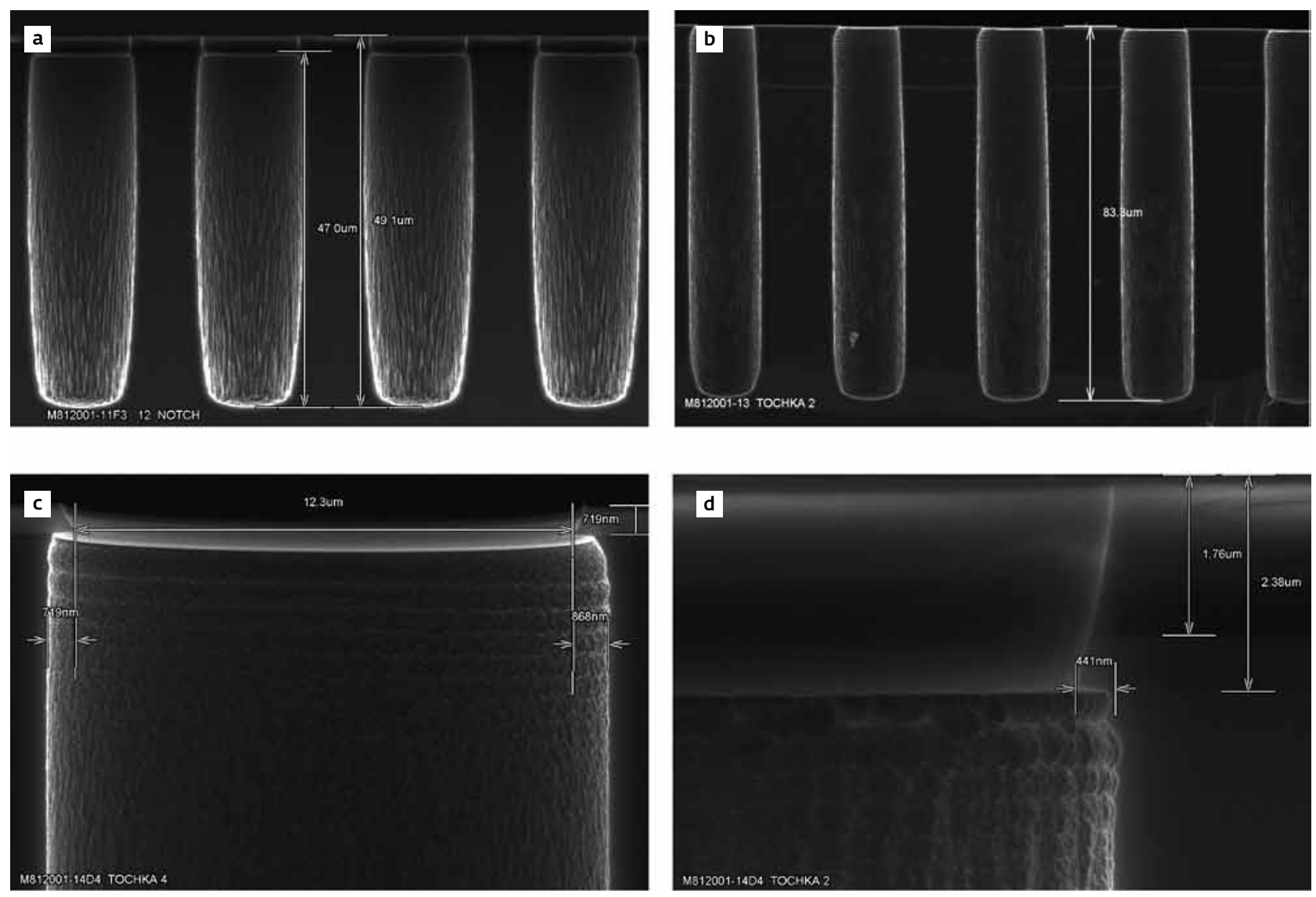

Рис.5. РЭМ-снимки после операции травления пластин диаметром 200 мм (a, b, $c, d)$

Fig.5. SEM images after etching of wafers dia $200 \mathrm{~mm}(a, b, c, d)$

- угол наклона профиля: $\approx 90 \pm 0,5^{\circ}$;

- величина scallop менее 132 нм.

Травление мелкощелевой изоляции, в отличие от глубокого травления кремния, проводилось в одностадийном процессе в реакторе установки "Плазма ТM 200-01" в смеси $\mathrm{C}_{4} \mathrm{~F}_{8}-\mathrm{SF}_{6}$, а для травления поликремниевых затворов использовалась смесь газов $\mathrm{SF}_{6}$ и $\mathrm{CHF}_{3}$, при этом $\mathrm{C}_{4} \mathrm{~F}_{8}$ и $\mathrm{CHF}_{3}$ обеспечивали боковую пассивацию стенок во время травления.

Результаты процесса травления мелкощелевой изоляции (a) и (b) и поликремниевых затворов (c) и (d) представлены на рис.7. С пластин (рис.7с и d), после операции травления, фоторезист был удален на установке "Плазма Тм 200-03".

Основные характеристики процесса травления:

- средняя скорость травления кремния : $\approx 1 \mathrm{M} \mathrm{кM} / \mathrm{Mин;}$

- средняя скорость травления поликремниевых затворов: $\approx 0,15 \mathrm{MkM} /$ мин;
- равномерность травления, измеренная в стандартных пяти точках: $\pm 3 \%$;

- угол наклона профиля: $\approx 89 \pm 0,5^{\circ}$.

Для обустройства технологического участка установки "Плазма ТМ 200-01", "Плазма TM 200-02", "Плазма ТМ 200-03" могут быть встроены в чистую комнату (рис.8).

\section{ОБСУЖДЕНИЕ РЕЗУЛЬТАТОВ ТРАВЛЕНИЯ}

Сужение профиля травления, заметное на рис.5а, связано с избытком полимера на стадии пассивации, об этом же говорит и образование миниатюрных борозд ближе ко дну канавки. Уменьшение полимера позволило выправить профиль травления и избавиться от борозд, однако некоторая бочкообразность в профиле травления осталась. Для исправления профиля травления было решено разбить стадию травления на два этапа. На первом этапе происходило скоростное удаление полимера со дна отверстия, на втором этапе производилось травление 


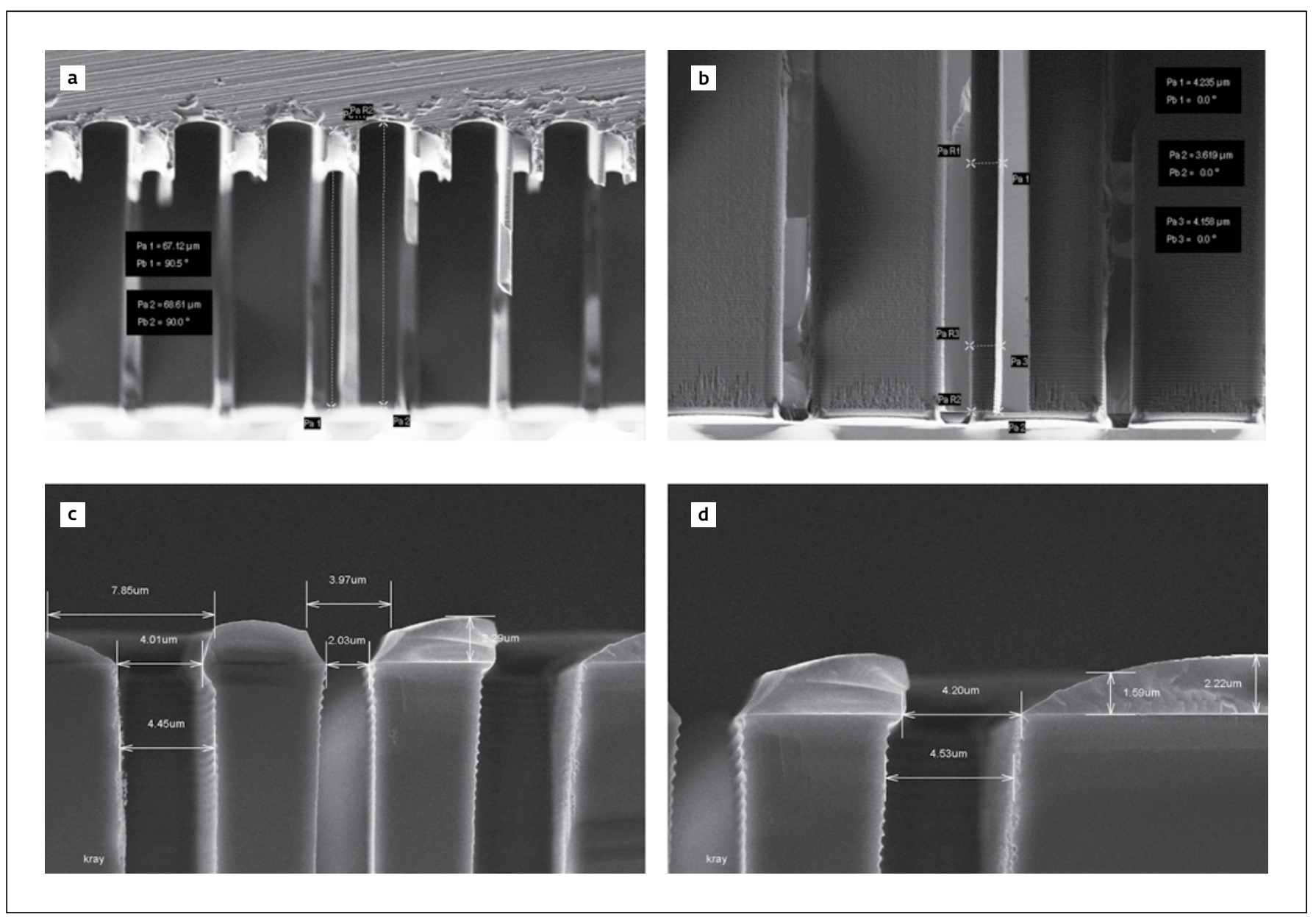

Рис.6. РЭМ-снимки после операции травления пластин диаметром 100 мм

Fig.6. SEM images after etching of wafers dia $100 \mathrm{~mm}$

кремния. Это позволило значительно уменьшить бочкообразность и выправить профиль, что видно на рис.5b, где глубина травления в два раза больше и профиль травления имеет вертикальное направление.

При полученных скоростях травления ( 2 мкм/мин) величина подтрава под маску (рис.5c и d) незначительна и не превышает 556 нм. Уменьшения подтрава под маску в случае необходимости можно добиться при уменьшении скорости травления.

При травлении щелей (рис.6) подтрав под маску не превышает 529 нм, несмотря на более высокую скорость травления ( 5 мкм/Мин), что может объясняться различной топологией структур, при этом величина шероховатостей стенок (scallop) увеличивается с ростом скорости травления, но не превышает 130 нм. Минимальное достигнутое значение шероховатости порядка 75 нм.

Продемонстрирована возможность получения гладких щелей при анизотропном травлении кремния (рис.7а и b) и поликремниевых затворов шириной до 100 нм (рис.7с и d) во фторсодержащих смесях без использования опасных газов $\mathrm{Cl}_{2}$ и $\mathrm{HBr}$.

Представленные режимы травления, возможно, не являются оптимальными для данных образцов, так как в ходе исследования не использовались все технологические возможности установки. Представленные результаты носят информационный характер с целью демонстрации возможностей оборудования.

\section{выводы}

Разработаны реактор для установки "Плазма ТМ 200-02" для формирования углублений в кремнии с применением Bosch-процесса на кремниевых пластинах диаметром до 200 мм и реактор для установки "Плазма ТМ 200-01" для формирования мелкощелевой изоляции и поликремниевых затворов. Для очистки пластин от полимеров и остатков фоторезиста разработан реактор для установки "Плазма Тм 200-03". 


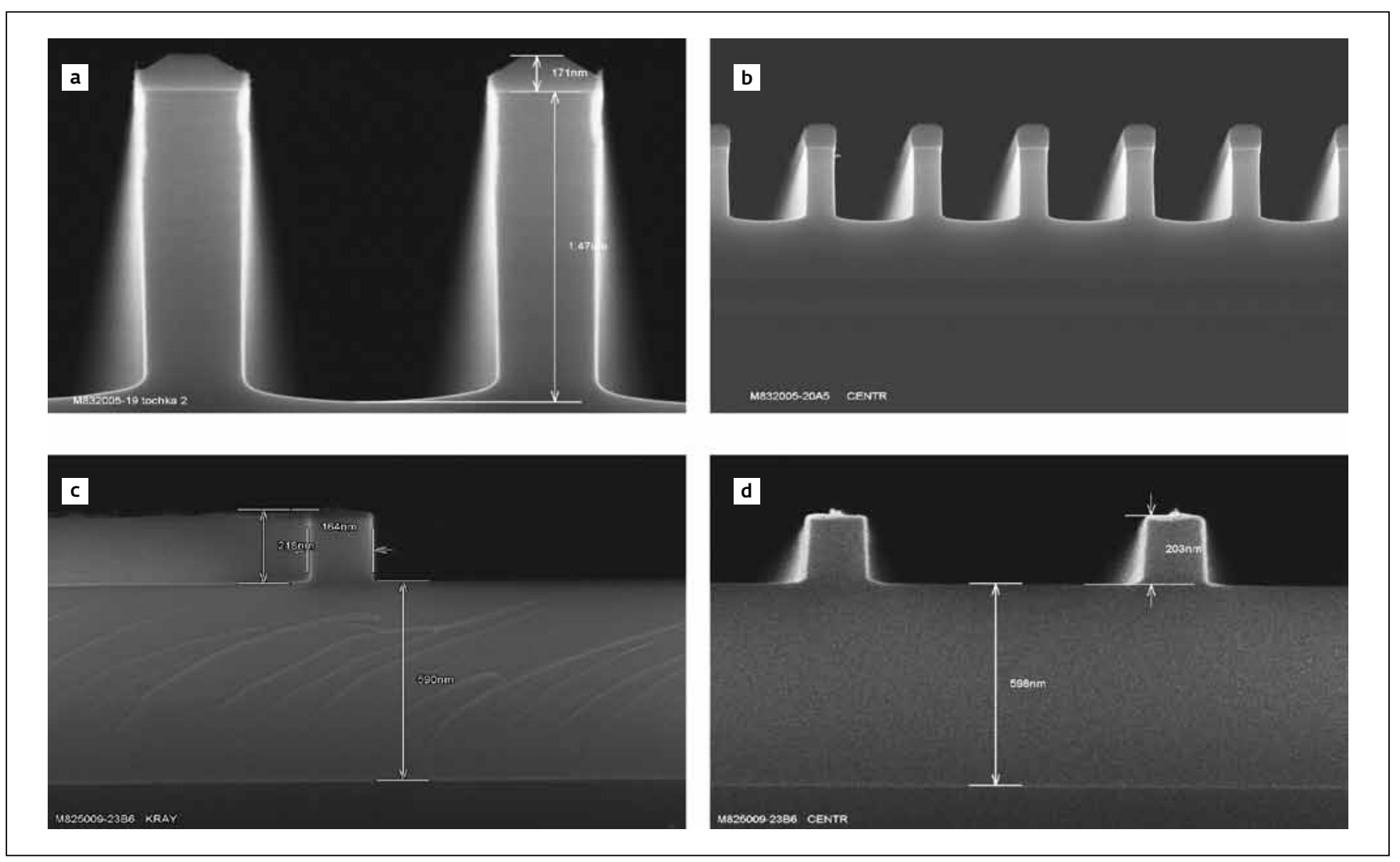

Рис.7. РЭМ-снимки пластин после операции травления мелкощелевой изоляции $(a, b)$ и операции травления поликремниевых затворов $(c, d)$

Fig.7. SEM images after etching of shallow trench isolation $(a, b)$ and polycrystalline silicon gate $(c, d)$

Получены значения неоднородности процесса травления в пределах 2-3\%, глубокие отверстия и щели с большим аспектным соотношением (более 15) и низкой шероховатостью стенок при скорости травления кремния до $5 \mathrm{mkM/мин,} \mathrm{что}$ позволяет применять установку в промышленном производстве.

\section{ЛИТЕРATУPA / REFERENCE}

1. Гущин О.П., Валеев А.С., Чамов А.А., Мицын Н.Г., Долгополов В.М., Одиноков В.В., Немировский В.Э., Иракин П.А. Исследование и разработка оборудования и технологии глубокого травления кремния // Микроэлектроника-2015. Интегральные схемы и микроэлектронные модули: проектирование, производство и применение. 2015. С. 561-564.

2. Амиров И.И., Морозов О.В., Кальнов В.А., Лукичев В.Ф., Орликовский А.А. Ключевые процессы технологии микросистемной техники: плазмохимические процессы глубокого анизотропного травления кремния //
Нанотехнологии и наноматериалы. 2012. № 4(66). С. 8-13.

3. Амиров И.И., Изюмов М.О., Морозов О.В., Анизотропное травление глубоких канавок в кремнии во фторсодержащей плазме // Наноинженерия. 2008, с. 653-656.

4. Oxford Plasma Technology, "Deep Si Etching at room temperature: the "Bosch" process" (http:// www.oxfordplasma.de/process/sibo_1.htm).

5. Oxford Plasma Technology, "High Rate Bosch Process by ICP Accelerator" (http://www. oxfordplasma.de/process/sibo_acc.htm).

6. Samsung begins to produce 64GB DDR4 modules based on TSV chips (http://www.kitguru.net/ components/memory/anton-shilov/samsungbegins-to-produce-64gb-ddr4-memory-modulesbased-on-tsv-chips/).

7. Micron's $320 \mathrm{~GB} / \mathrm{sec}$ Hybrid Memory Cube comes to market in 2013, threatens to finally kill DDR SDRAM (http://www.extremetech. com/computing/152465-microns-320 gbsechybrid-memory-cube-comes-to-market-in-2013threatens-to-finally-kill-ddr-sdram). 
ПРОМЫШЛЕННОЕ ВАКУУМНОЕ ТЕХНОЛОГИЧЕСКОЕ ОБОРУДОВАНИЕ АЛЯ ОБРАБОТКИ ПЛАСТИН Ф 200 ММ С ВОЗМОЖНОСТЬЮ ОБЪЕДИНЕНИЯ В КЛАСТЕРНЫЙ КОМПЛЕКС ПРИ ПОМОЩИ ТРАНСПОРТНО-ЗАГРУЗОЧНОЙ СИСТЕМЫ
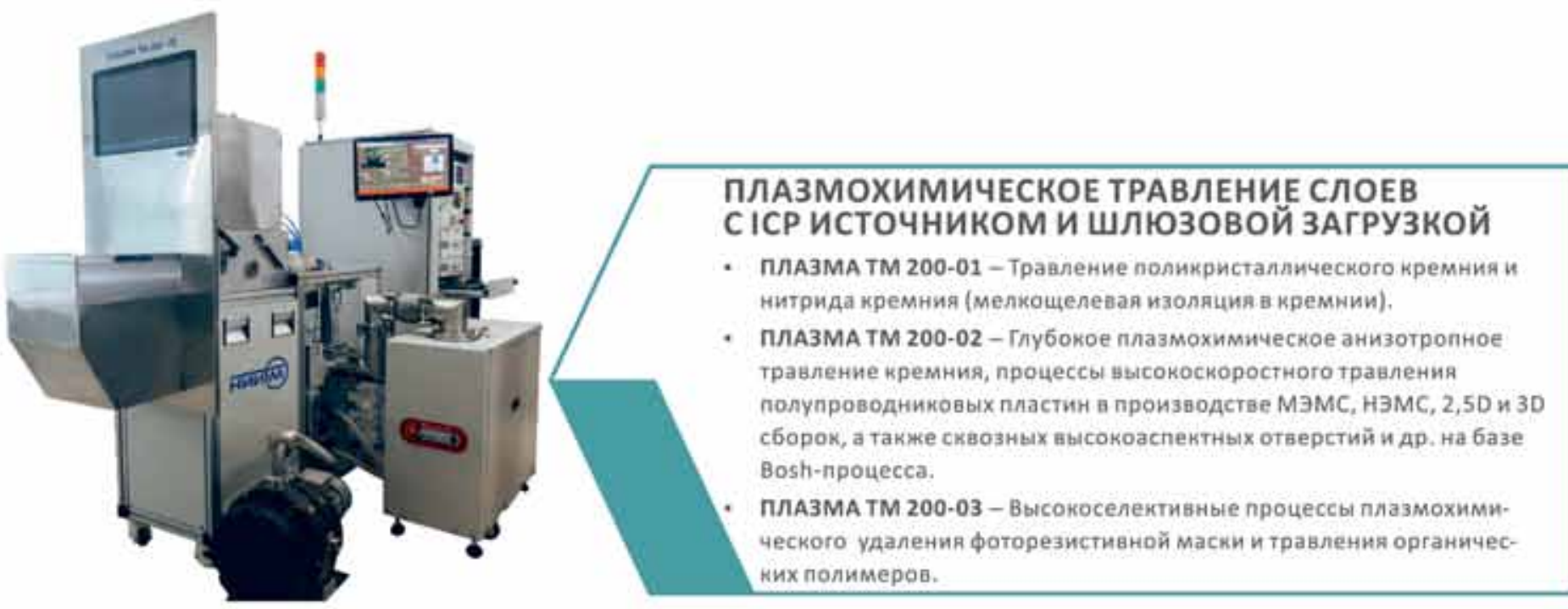

ПЛАЗМОХИМИЧЕСКОЕ ОСАЖДЕНИЕ СЛОЕВ ИЗ ГАЗОВОЙ ФАЗЫ С ІСР ИСТОЧНИКОМ И шЛЮЗОВОЙ ЗАГРУЗКОЙ (ALD)

ИЗОФАЗ ТМ 200-01 - Атомно-слоевое осаждение:

- Сверхтонких изолирующих слоев для МЭМС, жестких масок для микроэлектроники и пассивируощих слоев для фотовольтаники.

- Сверхтонких подзатворных диэлектринов с высоким значением диэлектрической постоянной (high-k), конформных барьерных и затравочных слоев в технологии TSV (Through silicon vias).

- Сверхтонких металлических слоев затворов в технолотии создания КМOП структур.

- Сверхтонких сегнетоэлектрических слоев конденсаторов в технологии создания устройств независимой памяти (FeRAM).
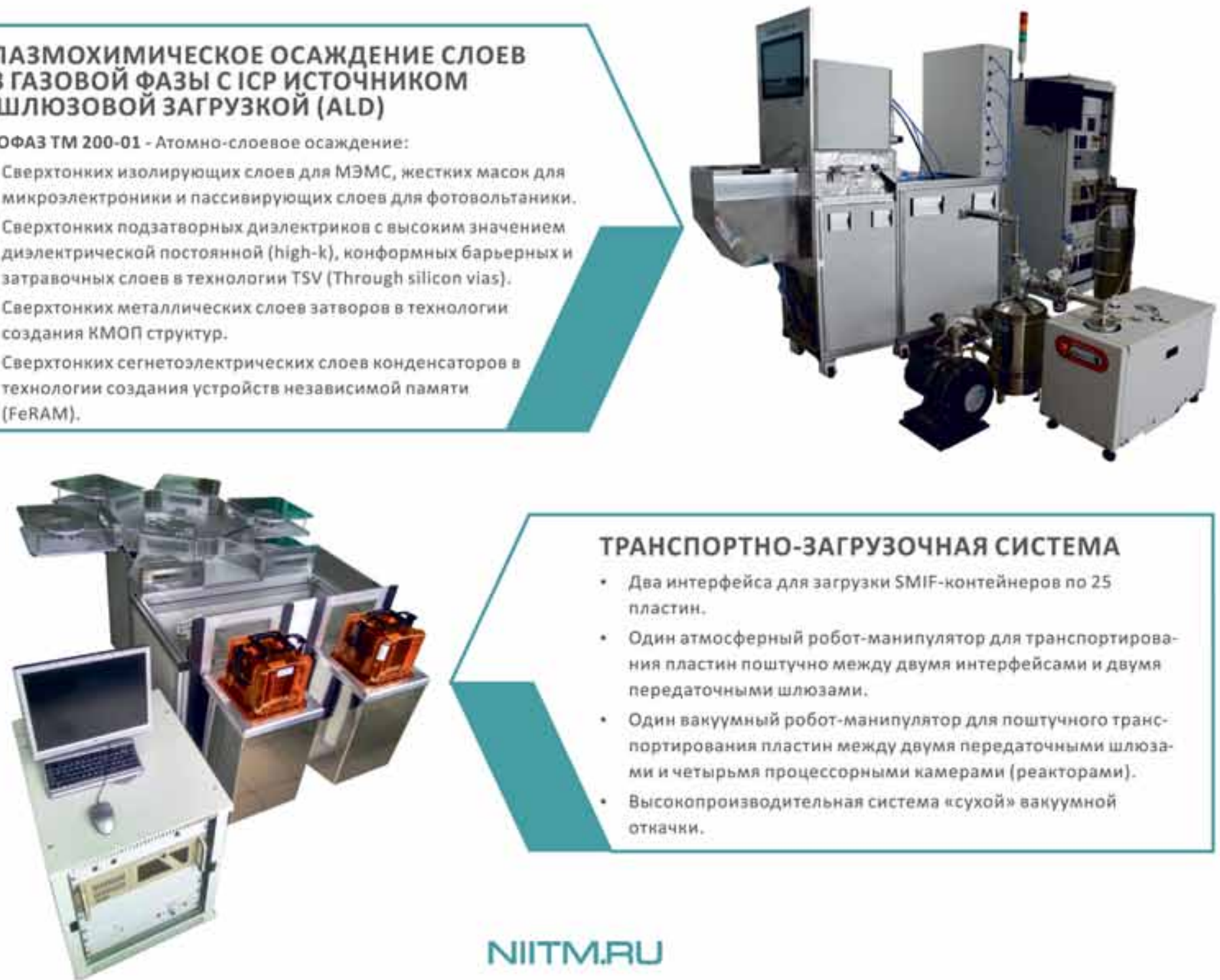